\title{
Efeito de diferentes técnicas extrativas no rendimento, atividade antioxidante, doseamentos totais e no perfil por clae-dad de dicksonia sellowiana (presl.). Hook, dicksoniaceae
}

OLIVEIRA, V.B. ${ }^{1,}$, ZUCHETTO, M. ${ }^{1}$, OLIVEIRA, C.F. ${ }^{1}$, PAULA, C.S. ${ }^{1}$, DUARTE, A.F.S. ${ }^{1}$, MIGUEL, M.D. ${ }^{1}$, MIGUEL, O.G. ${ }^{1}$

Universidade Federal do Paraná, Departamento de Farmácia, Programa de Pós Graduação em Ciências Farmacêuticas. Av. Pref. Lothário Meissner, 632 -. Jardim Botânico, CEP 80210-170, Curitiba, PR, Brasil. *Autor para correspondência: vinicius.bednarczuk@hotmail.com

\begin{abstract}
RESUMO: A espécie Dicksonia sellowiana, conhecida popularmente como xaxim, é uma samambaia natural do continente americano e encontrada no Brasil na Mata Atlântica. Em 2001 sua utilização para confecção de vasos para jardinagem foi proibida, e a mesma foi inserida na lista do IBAMA como espécie ameaçada de extinção. O presente trabalho descreve o efeito de diferentes técnicas de extração, incluindo ultra-som, turbólise, maceração, infusão, decocto e soxhlet utilizando etanol e solvente hidroalcoólico $70 \%$, sob aspectos físicos e químicos. Foi avaliado o rendimento de cada extração, o perfil por CLAE-DAD, o conteúdo de polifenóis, flavonoides, proantocianidinas e esteroides além das atividades antioxidantes pelos métodos DPPH e redução do complexo fosfomolibdênio. Os dados foram avaliados estatisticamente através de desvio padrão, Tuckey e PCA. Os resultados demonstraram que a extração por Soxhlet utilizando ambos os solventes é a que possui maior rendimento final, porém o rendimento não está diretamente relacionado com o aumento nos teores de bioativos totais e atividades antioxidantes. As extrações por decocção e turbólise utilizando solvente hidroalcoólico foram as que apresentaram melhores resultados nos teores totais e na atividade antioxidante, resultados que ficam evidentes quando avaliados por PCA, demonstrando que este solvente e estas extrações são mais seletivas no estudo proposto.
\end{abstract}

Palavras-chave: Dicksonia sellowiana; técnicas de extração; bioativos; atividade antioxidante.

\begin{abstract}
Effect of different extraction techniques on the yield, antioxidant activity, total dosages, and profile by hplc-dad of Dicksonia sellowiana (Presl.). Hook, dicksoniaceae. The species Dicksonia sellowiana, popularly known as xaxim, is a fern native to the Americas and found in Brazil in the Atlantic Forest. In 2001, its use for making gardening pots was banned, and it was added to the IBAMA [Brazilian Institute of the Environment and Renewable Natural Resources] list as an endangered species. This paper describes the effect of different extraction techniques - including ultrasound, turbolysis, maceration, infusion, decoction, and soxhlet using ethanol and $70 \%$ hydroalcoholic solvent on its physical and chemical aspects. The yield of each extraction was evaluated, as well as the profile by HPLC-DAD, the polyphenol content, flavonoids, proanthocyanidins, and steroids, in addition to the antioxidant activities through the DPPH and phosphomolybdenum complex reduction methods. The data were statistically analyzed through standard deviation, Tukey, and PCA. The results showed that the soxhlet extraction using both solvents had the highest overall yield; however, the yield is not directly related to the increase in total bioactive content and antioxidant activities. Extractions by decoction and turbolysis using a hydroalcoholic solvent exhibited the best results in total content and antioxidant activity - results that are evident when evaluated through PCA, demonstrating that this solvent and these extractions are the most selective in the proposed study.
\end{abstract}

Keywords: Dicksonia sellowiana; extraction techniques; bioactives; antioxidant activity.

\section{INTRODUÇÃO}

A espécie Dicksonia sellowiana conhecida popularmente como xaxim, samambaiaçu e samambaiaçu imperial, é uma samambaia pertencente à família Dicksoniaceae, uma pequena 
família de fetos arborescentes encontradas em regiões tropicais do hemisfério sul, com espécies que podem chegar a 4 metros de comprimento (Joly, 1985; Mielke, 2002). Esta espécie é muito encontrada no Brasil nas regiões sul e sudeste, tendo registros também desde o sul do México até o Uruguai (Tryon \& Tryon, 1982; Fernandes, 1997).

O uso popular possui registros da utilização desta espécie de diversas maneiras (via oral, tópica ou por inalação) para o tratamento da asma, da pele, doenças cardiovasculares e doença parasitária (Corrêa, 1984; Marquesini, 1995). Entre os metabólitos secundários já identificados destacase a presença de polifenóis (flavonoides e taninos) e as substâncias ácido gálico e ácido protocatecuico (Oliveira, 2012). Estudos demonstram que a espécie possui atividade antioxidante frente à oxidação lipídica, sem possuir toxicidade em modelos in vitro (Oliveira et al., 2015).

Devido à exploração comercial dessa planta para a confecção de vasos para jardinagem e floricultura, o CONAMA - Conselho Nacional de Meio Ambiente - elaborou a resolução 278/2001, que veta o comércio, colocando a planta endêmica da Mata Atlântica, na lista oficial do IBAMA - Instituto Brasileiro do Meio Ambiente e dos Recursos Naturais Renováveis, de espécies brasileiras ameaçadas de extinção (Portaria/IBAMAn ${ }^{\circ}$. 37-N/92 e COPAM 085/97) e no Apêndice II da Convenção Internacional sobre o Comércio Internacional de Espécies da Fauna e Flora em Perigo de Extinção - CITES (2015).

A busca por compostos bioativos de origem natural com alta capacidade antioxidante aumentou consideravelmente nas duas ultimas décadas, principalmente devido ao seu potencial preventivo e no tratamento de doenças cardiovasculares, doenças crônicas e neurodegenerativas (Gil-Chávez et al., 2013). Neste sentido, encontrar métodos extrativos eficientes bem como a caracterização de compostos bioativos a partir de fontes naturais é de grande desafio para os pesquisadores.

Os métodos extrativos para obtenção de extratos vegetais incluem maceração, infusão, percolação, decocção, extração contínua quente (Soxhlet), extração em contra-corrente, extração assistida por microondas, ultra-som, fluido supercrítico e turbólise. Além dos métodos extrativos, são diversos os fatores que influenciam na extração, como a parte do material vegetal utilizada, a origem deste, o grau de processamento, o tamanho da partícula, o solvente utilizado, o tempo de extração, temperatura, polaridade e concentração do solvente (Tiwari et al., 2011). O solvente utilizado e a polaridade podem afetar a transferência de elétrons e de átomos de hidrogênio, que é aspecto-chave na extração de polifenóis e consequentemente na capacidade antioxidante (Rockenbach et al., 2008).

Muitos estudos vêm demonstrando a influência da extração no teor de metabólitos secundários (Vongsak et al, 2013; Bampouli et al, 2014; Karabegović et al, 2014). Neste sentido, o objetivo do presente estudo foi comparar os rendimentos de extração, avaliação do perfil cromatográfico, teor total de polifenóis, flavonoides, proantocianidinas e esteroides, além das atividades antioxidantes pelos métodos DPPH e fosfomolibdênio de extratos de frondes de xaxim, obtidos por ultrassom, turbólise, maceração, infusão, decocto e Soxhlet utilizando como solventes extração etanólica e extração hidroalcoólica $70 \%$.

\section{MATERIAL E MÉTODOS \\ Material Vegetal}

As frondes de Dicksonia sellowiana (Presl.)

Hook, da espécie adulta em fase vegetativa, foram coletadas na cidade de Inácio Martins, Paraná, com localização via GPS S25 29' 35,7" WO 51 '12' 00.0", em abril de 2010. A identificação e depósito da exsicata foi realizada no Museu Botânico de Curitiba sob o número 358323. Por tratar-se de uma espécie ameaçada de extinção, este estudo possui autorização do IBAMA para acesso ao patrimônio genético por meio da Autorização n. ${ }^{\circ} 023 / 2010$, para fins de pesquisa científica, atendendo os requisitos descritos na resolução $n^{\circ}$ 35, de 27 de abril de 2011 que dispõe sobre a regularização de atividade de acesso ao patrimônio genético (Brasil, 2011).

\section{Preparo dos Extratos Vegetais}

As frondes foram secas em estufa na temperatura de $50{ }^{\circ} \mathrm{C}$ por um período aproximado de 36 horas, trituradas em moinho de facas/martelo e tamisado para obter diversas granulometrias, para o preparo dos extratos foi utilizado pó abaixo de $500 \mu \mathrm{m}$. Para os seis métodos extrativos propostos foi utilizado a mesma proporção da droga vegetal com o solvente extrator a qual foi de $10 \mathrm{~g}$ para 150,00 $\mathrm{mL}$. Foram utilizados dois solventes diferentes nas extrações, o primeiro utilizando etanol $92,8 \%$ e o segundo utilizando solvente hidroalcoólico $70 \%$ e todos os 12 extratos vegetais foram filtrados e concentrados em rota-evaporador.

\section{Métodos a frios \\ Ultrassom}

O extrato bruto por ultrassom foi preparado por um período de 90 minutos em temperatura ambiente. Foram elaborados dois extratos vegetais por este método, o extrato bruto por ultrassom etanólico (US-E) e o extrato bruto por ultrassom hidroalcoólico (US-HA). 


\section{Turbólise}

O extrato bruto por turbólise foi preparado utilizando equipamento Ultraturrax por um período de 10 minutos a $4000 \mathrm{rpm}$ em temperatura ambiente. Foram elaborados dois extratos vegetais por este método, o extrato bruto por turbólise etanólico (TUR-E) e o extrato bruto por turbólise hidroalcoólico (TUR-HA).

\section{Maceração}

O extrato bruto obtido por maceração foi preparado utilizando dois frascos ambares fechados hermeticamente por um período de 7 dias sem iluminação. Foram elaborados dois extratos vegetais por este método, o extrato bruto por maceração etanólico (MAC-E) e o extrato bruto por maceração hidroalcoólico (MAC-HA).

\section{Métodos a quente \\ Decocção}

O extrato bruto por decocção foi elaborado utilizando dois frascos ambares em banho-maria a $90^{\circ} \mathrm{C}$ por um período de 15 minutos. Esta temperatura garantiu a ebulição do solvente utilizado. Foram elaborados dois extratos vegetais por este método: o extrato bruto por decocção etanólico (DEC-E) e o extrato bruto por decocção hidroalcoólico (DEC-HA).

\section{Infusão}

Para estas extrações, os solventes foram levados até a temperatura de ebulição, e, após este processo, foram vertidos em frascos ambarares que continham o material vegetal e tampados por um período de 30 minutos. Foram elaborados dois extratos vegetais por este método: o extrato bruto por infusão etanólico (INF-E) e o extrato bruto por infusão hidroalcoólico (INF-HA).

\section{Soxhlet}

Para elaboração do extrato bruto obtido por Soxhlet foi observado a limpidez do solvente extrator, o que caracterizou como a extração total, totalizando aproximadamente 8 horas de extração. Foram elaborados dois extratos vegetais por este método: o extrato bruto por soxhlet etanólico (SOX-E) e o extrato bruto por soxhlet hidroalcóolico (SOX-HA).

\section{Determinação do resíduo seco}

$1,00 \mathrm{~mL}$ de cada extrato foi exatamente medido e transferido para cápsulas de porcelana, previamente taradas. As cápsulas foram colocadas em estufa sob temperatura de $100^{\circ} \mathrm{C}$, até a secura e peso constante. As cápsulas foram novamente pesadas e calculados o teor de sólidos em $10 \mathrm{~g}$ da droga vegetal e o desvio padrão.

\section{Análise cromatográfica por CLAE-DAD}

Os extratos brutos de Dicksonia sellowiana foram diluídos em $\mathrm{MeOH}$ a uma concentração de $20,00 \mathrm{mg} \cdot \mathrm{mL}^{-1}$ e submetidos à análise por CLAE Merck Hitachi - Elite Lachrom, com detector diodo (DAD) em $295 \mathrm{~nm}$, coluna XTerra® RP18 $5 \mu \mathrm{m}$, $4,6 \times 250 \mathrm{~mm}$, volume de injeção de $20 \mu \mathrm{L}$, fluxo 1,00 $\mathrm{mL} \mathrm{min}^{-1}$. Como fase móvel foi utilizado gradiente de concentração o sistema $\mathrm{H}_{2} \mathrm{O}: \mathrm{H}_{3} \mathrm{PO}_{4}$ a $0,1 \%$ (A) e $\mathrm{MeOH}(\mathrm{B})$ na seguinte programação: 1-45 min, iniciando com $10 \%$ de fase B e finalizando em 45 min com $100 \%$ de fase B. O MeOH utilizado foi grau HPLC (TEDIA) e a água MilliQ.

\section{Quantificação de metabólitos Doseamento de polifenóis totais}

Para determinação do teor de fenólicos totais, os extratos brutos diluídos em metanol (1000 $\mu \mathrm{g} \cdot \mathrm{mL}^{-1}$ ) foram adicionados $0,2 \mathrm{~mL}$ das amostras em tubo de ensaio e este completado para $3.2 \mathrm{~mL}$ com água destilada, após total solubilização foi adicionado $0,2 \mathrm{~mL}$ de reativo de Folin-Ciocalteau novamente homogeneizado e adicionado $0,4 \mathrm{~mL}$ de carbonato de sódio a $10 \%$, agitado e depois 30 minutos de repouso em temperatura ambiente (Slinkard \& Singleton, 1977). Após este período foram realizadas as leituras em espectrofotômetro à $760 \mathrm{~nm}$ utilizando curva de calibração de ácido gálico nas concentrações de 2,5; 5; 7,5; 10; 12,5; $15 ; 17,5$ e $20 \mu \mathrm{g} \cdot \mathrm{mL}^{-1}$ como padrão, as leituras foram realizadas em triplicata. Os teores de fenólicos totais foram determinados em miliequivalente de ácido gálico ( $\mathrm{mEqG}$ ) por grama de extrato bruto, utilizando a seguinte equação com base na curva de calibração: $y=0,0392 x-0,0583, R^{2}=0,9964$.

\section{Doseamento de flavonoides totais}

Os extratos brutos diluídos em metanol $\left(1000 \mu \mathrm{g} \cdot \mathrm{ml}^{-1}\right)$ foram adicionados a $2,00 \mathrm{ml} \mathrm{de} \mathrm{AlCl}_{3}$ $2 \%$, e o volume da amostra foi completado para 2,00 $\mathrm{mL}$. Após 60 minutos, foram realizadas as leituras em espectrofotômetro à $420 \mathrm{~nm}$ utilizando curva de calibração de quercetina nas concentrações de 5 , $10,15,20,25$ e $30 \mu \mathrm{g} \cdot \mathrm{mL}^{-1}$ como padrão. As leituras foram realizadas em triplicata (Chang et al., 2002). Os teores de flavonoides totais foram determinados em miliequivalente de quercetina ( $\mathrm{mEqQ}$ ) por grama de extrato bruto, utilizando a seguinte equação com base na curva de calibração: $y=0,0314 x-0,0164$, $\mathrm{R}^{2}=0,9996$.

\section{Doseamento de protoantocianidinas totais}

Para determinação do teor de protoantocianidinas totais, diluiu-se os extratos brutos em metanol (1000 $\left.\mu \mathrm{g} \cdot \mathrm{mL}^{-1}\right)$ e este adicionado a 3,00 $\mathrm{mL}$ de uma solução reagente. Para o preparo da solução reagente foi feita uma solução de

Rev. Bras. PI. Med., Campinas, v.18, n.1, supl. I, p.230-239, 2016. 
vanilina $1 \%$ em metanol e solução de HCL $8 \%$ em metanol após o preparo estas foram misturadas na proporção de 1:1. A leitura foi realizada após 20 minutos incubados em banho-maria a $30{ }^{\circ} \mathrm{C}$ em espectrofotômetro à $500 \mathrm{~nm}$ utilizando curva de calibração de catequina nas concentrações de 25, 50, 75, 100, 125 e $150 \mu \mathrm{g} \cdot \mathrm{mL}^{-1}$ como padrão. As leituras foram realizadas em triplicata (Burns, 1971). Os teores de protoantocianidinas totais foram determinados em miliequivalentes de catequina (mEqC) por grama de extrato bruto, utilizando a seguinte equação com base na curva de calibração: $y=0,0009 x+0,0048, R^{2}=0,9952$.

\section{Doseamento de esteroides totais}

Determinada concentração dos extratos brutos foram diluídos em clorofórmio $\left(1000 \mu \mathrm{g} \cdot \mathrm{mL}^{-1}\right)$ este completado para $2,00 \mathrm{~mL}$ com clorofórmio e adicionado $2,00 \mathrm{~mL}$ do reativo de LibermannBurchard e $5,00 \mathrm{~mL}$ de $\mathrm{CHCl}_{3}$, as amostras foram guardadas protegidas da luz, à temperatura ambiente, por 15 minutos. A presença de esteróis produz coloração verde característica, cuja absorbância foi determinada em espectrofotômetro, a $640 \mathrm{~nm}$ utilizando como curva de calibração de esteroides o padrão estigmasterol nas concentrações de $25,50,75,100,125 \mu \mathrm{g} . \mathrm{mL}^{-1}$, as leituras foram realizadas em triplicata (Kim \& Goldberg, 1969). Os teores de esteroides totais foram determinados em miliequivalentes de estigmasterol ( $\mathrm{mEqE}$ ) por grama de extrato bruto, utilizando a seguinte equação com base na curva de calibração: $y=0,0016 x-0,0004$, $\mathrm{R}^{2}=0,9963$.

\section{Determinação da atividade antioxidante: Redução do radical livre DPPH}

O potencial de redução do radical DPPH (2,2-difenil-1-picrilhidrazila) dos extratos foi analisado espectrofotometricamente a $518 \mathrm{~nm}$ (Mensor et al., 2001). Foram preparadas cinco soluções metanólicas de cada extrato bruto nas concentrações de 5,0 a $65,0 \mu \mathrm{g} \cdot \mathrm{mL}^{-1}$, e para o padrão vitamina $\mathrm{C}$ de 2 a $8 \mu \mathrm{g} \cdot \mathrm{mL}^{-1}$. Destas soluções, 2,5 $\mathrm{mL}$ foram adicionados a $1,00 \mathrm{~mL}$ de uma solução metanólica de DPPH na concentração de $0,03 \mathrm{mmol}$. $\mathrm{mL}^{-1}$. Como controle negativo foi utilizado $2,5 \mathrm{~mL}$ de metanol e 1,00 mL da solução de DPPH. Após 30 minutos de incubação à temperatura ambiente, protegido da luz, a redução do radical livre DPPH foi mensurada. A determinação da IC50 (Concentração Inibitória de 50\%) foi obtida por regressão linear dos pontos plotados graficamente e através da equação da reta obtido os valores de IC50.

\section{libdênio}

Poder Redutor pelo Método de FosfomoO método de redução pelo complexo fosfomolibdênio, descrito por Prieto et al. (1999), avalia a capacidade antioxidante total de uma mistura complexa de compostos, tanto de componentes lipofílicos quanto de hidrofílicos. O complexo fosfomolibdênico é formado pela reação da solução de $\mathrm{Na}_{3} \mathrm{PO}_{4}\left(28,00 \mathrm{~mL}, 0,1 \mathrm{~mol} . \mathrm{L}^{-1}\right)$ com solução de $\left(\mathrm{NH}_{4}\right)_{6} \mathrm{Mo}_{7} \mathrm{O}_{24} \cdot 4 \mathrm{H}_{2} \mathrm{O}(12,00 \mathrm{~mL}, 0,03 \mathrm{~mol} . \mathrm{L}-1)$ e solução de $\mathrm{H}_{2} \mathrm{SO}_{4}\left(20,00 \mathrm{~mL}, 3 \mathrm{~mol} . \mathrm{L}^{-1}\right)$, em meio aquoso, sendo o volume final, ajustado com $\mathrm{H}_{2} \mathrm{O}$ destilada para $100,00 \mathrm{~mL}$. Possui coloração amarela, tornando-se verde à medida que se reduz. Foram preparadas soluções metanólicas com concentração final de $200 \mu \mathrm{g} \cdot \mathrm{mL}^{-1}$. Destas, $0,3 \mathrm{~mL}$ foram adicionados a $3,00 \mathrm{~mL}$ de solução reagente do complexo fosfomolibdênio. Os tubos foram fechados e mantidos em banho-maria a $95^{\circ} \mathrm{C}$ por 90 minutos. Após resfriamento, foi feita a leitura a 695 nm, em um espectrofotômetro para obtenção das absorbâncias, usando $0,3 \mathrm{~mL}$ de metanol com $3,00 \mathrm{~mL}$ do reagente como branco. A capacidade antioxidante das amostras é expressa em relação a vitamina C (200 $\left.\mu \mathrm{g} \cdot \mathrm{mL}^{-1}\right)$ cuja atividade antioxidante de referência foi considerada $100 \%$. O ensaio foi realizado em triplicata.

\section{Estatística}

Todos os cálculos foram realizados nos softwares Microsoft Office Excel 2010 e SISVAR 5.3. Os dados foram submetidos à análise de variância (ANOVA) e para comparações entre as médias dos índices de atividade, utilizou-se o teste de Tukey. As diferenças foram consideradas estatisticamente significantes quando $P<0,05$. $A$ análise multivariada foi realizada utilizando $o$ software Statistica 8.0. Os dados de conteúdos totais e atividades antioxidantes foram analisados por meio de análise de componentes principais (PCA) para verificar agrupamentos que poderiam ser usados para mostrar a similaridade nos processos extrativos.

\section{RESULTADOS E DISCUSSÃO}

Os rendimentos de extração das frondes previamente secas e trituradas estão dispostos na figura 1. Levando em consideração os resultados, pode ser visto que o método extrativo influencia diretamente nos rendimentos dos extratos e que, além do método utilizado, o solvente também influencia no conteúdo final da extração. O rendimento de extração utilizando etanol variou entre 365 mg (US-E) a 1.540 mg (SOX-E) em 10 gramas de planta seca, uma diferença de \pm $76 \%$ entre as extrações, por outro lado utilizando solvente hidroalcoólico $70 \%$ o rendimento variou entre $1.040 \mathrm{mg}$ (US-HA) a $1.480 \mathrm{mg}$ (SOX-HA) uma diferença de $\pm 30 \%$ entre os métodos. O método por

Rev. Bras. PI. Med., Campinas, v.18, n.1, supl. I, p.230-239, 2016. 
Soxhlet demonstrou a melhor eficiência de extração independente do solvente utilizado, que variou \pm $4 \% \mathrm{em}$ ambas as extrações. Esta diferença entre os rendimentos de extração neste método devese ao fato do etanol ser uma molécula anfif́lica e extrair tanto substâncias com caráter apolar quanto polar, resultados semelhantes a outros estudos realizados (Karabegović et al., 2014). Considerando que o método utilizando Soxhlet foi realizado até a exaustão completa do material vegetal, com tempo de \pm 8 horas, estes rendimentos foram aceites como teor total de extrato de frondes de Dicksonia sellowiana.

Levando em consideração ambos os solventes utilizados na extração, observa-se que o solvente hidroalcoólico a $70 \%$ possui melhor rendimento em praticamente todos os métodos extrativos, exceto por Soxhlet que variou em $\pm 4 \%$. Este fator demonstra que o solvente hidroalcoólico é mais seletivo para a extração dos metabólitos presentes nas frondes de Dicksonia sellowiana, estudos anteriores identificaram a presença de taninos hidrolisáveis, taninos condensados e flavonoides glicosilados derivados da quercetina e kaempferol, grupos de metabolismo secundário et al., 2011).

Resultados semelhantes foram observados em outros estudos (Gnoatto et al., 2007; Karabegović et al., 2014), onde a extração por Soxhlet utilizando etanol obtiveram os melhores rendimentos extrativos. Os resultados deste estudo demonstram que o método extrativo, o solvente utilizado, o tempo e a temperatura influenciam diretamente levar em consideração que muitas substâncias são termolábeis e outras podem sofrer modificações estruturais irreversíveis em altas temperaturas (Yamini et al., 2008; Tiwari et al., 2011).

O perfil cromatográfico dos extratos brutos foi analisado em $295 \mathrm{~nm}$, comprimento de onda que a com caráter mais polar (Oliveira, 2012; Rattmann no rendimento total do extrato, porém é preciso

maioria dos picos cromatográficos apresentou maior intensidade. Através da analise dos cromatogramas é possível verificar uma similaridade entre os métodos a frio e a quente, variando na área de determinados picos cromatográficos, principalmente na região entre 20 a 30 minutos. Observa-se na figura 2 que há diferença na área de diversos picos cromatográficos comparando os métodos extrativos a frio e o solvente utilizado. A principal diferença cromatográfica além da área dos picos cromatográficos está na região entre 35 a 45 minutos onde os métodos etanólicos apresentaram maior concentração de picos cromatográficos, devido a substâncias de caráter mais apolar, característica que nos métodos hidroalcoólicos foi minimizada pela polaridade mais alta do solvente.

Na figura 3, o perfil cromatográfico dos métodos obtidos a quente é possível verificar a mesma similaridade encontrada nos cromatogramas da figura 2, diferenças nas áreas dos sinais na região entre 20 a 30 minutos e na região de 35 a 45 minutos. Os cromatogramas que apresentaram maior área dos picos na região entre 20 e 30 minutos como as amostras TUR-HÁ, INF-HÁ e DEC-HÁ obtiveram os melhores resultados no doseamento de polifenóis e flavonoides totais, concluindo que este aumento de sinais deve-se a presença destes metabólitos.

Estudo realizado por Herzi et al. (2013), demonstra diferenças significativas quanto a natureza dos componentes e a quantidade destes no que se diz respeito ao método de extração, além de detectar na extração por Soxhlet uma alta quantidade de substâncias de alta massa molecular.

$\mathrm{Na}$ análise de doseamentos de grupos de metabólitos secundários utilizando métodos espectrofotométricos (tabela 1), observa-se que o extrato DEC-HÁ foi o que apresentou maior rendimentos de polifenóis $\left(256,5 \mathrm{mEqG} . \mathrm{g}^{-1}\right)$, flavonoides $\left(44,8 \mathrm{mEqQ} \cdot \mathrm{g}^{-1}\right)$ e proantocianidinas $\left(140,4 \mathrm{mEqC} \cdot \mathrm{g}^{-1}\right)$, este alto teor de substâncias
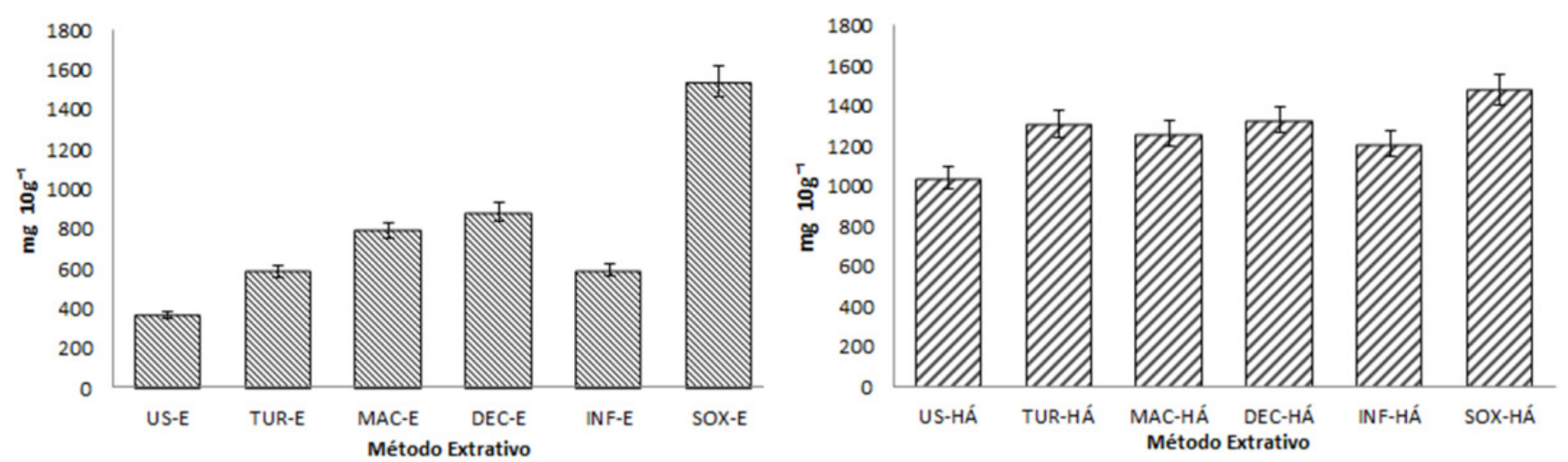

FIGURA 1. Rendimento de extração etanólico e hidroalcoólico obtidos por diferentes técnicas a partir de frondes de Dicksonia sellowiana

Rev. Bras. PI. Med., Campinas, v.18, n.1, supl. I, p.230-239, 2016. 

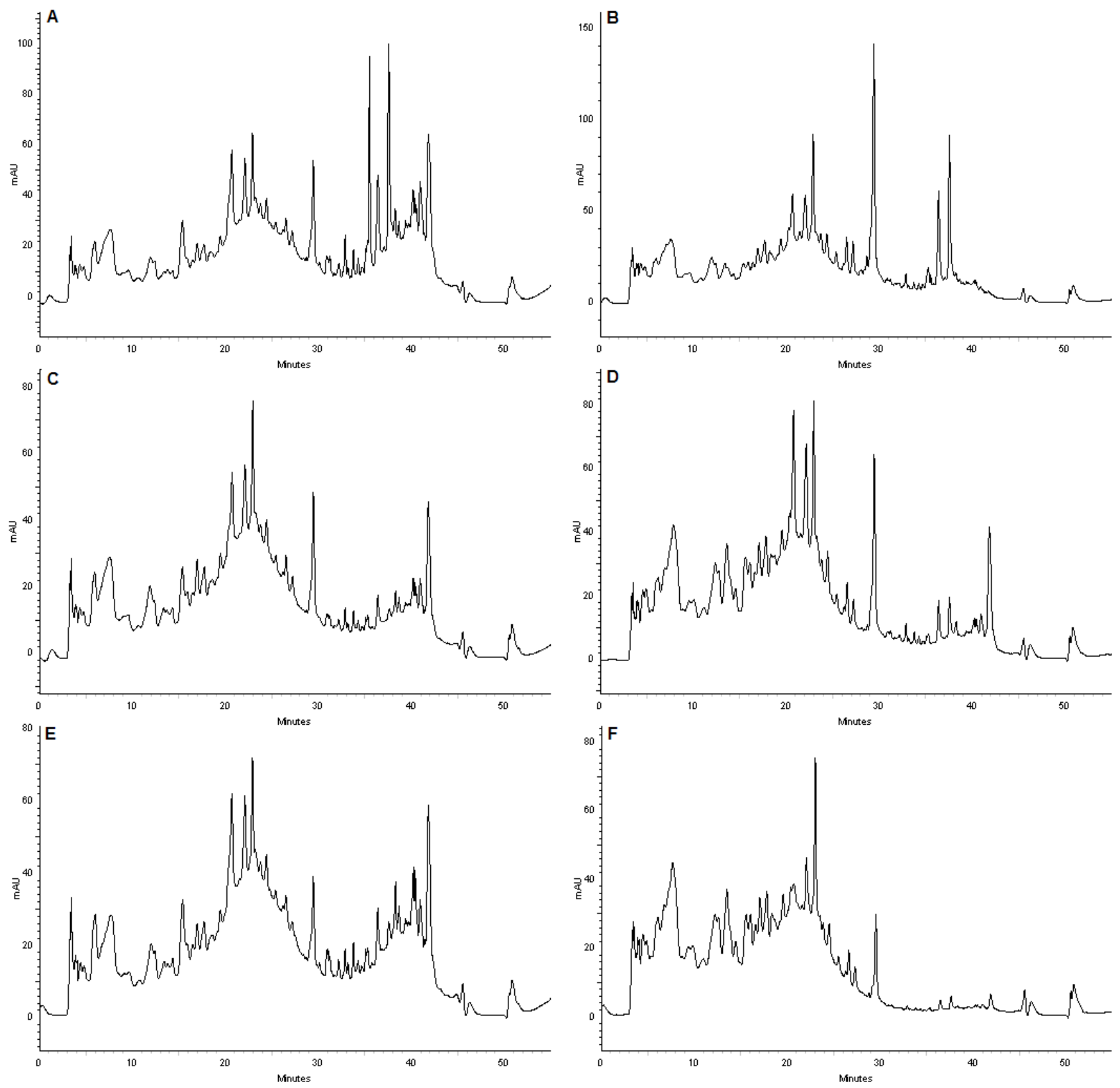

FIGURA 2. Perfil cromatográfico das extrações a frio das frondes de D. sellowiana. A) MAC-E, B) MAC-HÁ, C) TUR-E, D) TUR-HÁ, E) US-E, F) US-HÁ

fenólicas estão relacionadas com a maior atividade antioxidante pelos métodos DPPH $\left(25,2 \mu \mathrm{g} \cdot \mathrm{mL}^{-1}\right)$ e redução do complexo fosfomolibdênio $(58,4 \%)$. Outros estudos demonstram esta correlação entre conteúdo de substâncias fenólicas e atividade antioxidante (Campos et al., 2014; Veber et al., 2015).

Na maioria das extrações a utilização do solvente hidroalcoólico favoreceu a extração de substâncias fenólicas diminuindo o IC50 no método DPPH e aumentando a atividade pelo método fosfomolibdênio. Na extração SOX-E os resultados de polifenóis totais $\left(180,4 \mathrm{mEqG} \cdot \mathrm{g}^{-1}\right)$ e flavonoides totais $\left(24,01 \mathrm{mEqQ} \mathrm{g}^{-1}\right)$ foram superiores ao SOXHÁ, menos no teor de proantocianidinas $(67,0$ $\left.\mathrm{mEqC} . \mathrm{g}^{-1}\right)$, a atividade antioxidante em ambas as extrações foram semelhantes. Entre os métodos testados, o que mais se destacou nos doseamentos totais seguido pela atividade antioxidante foram às extrações por DEC-HA, TUR-HÁ, TUR-E e INFHA. Outro fator analisado foi o teor de esteroides totais, que não está relacionado diretamente à atividade antioxidante. $\mathrm{Na}$ tabela 1 verifica-se que os solventes etanólicos apresentaram teores superiores de esteroides que nas extrações com solvente hidroalcoólico, fator que justifica-se 

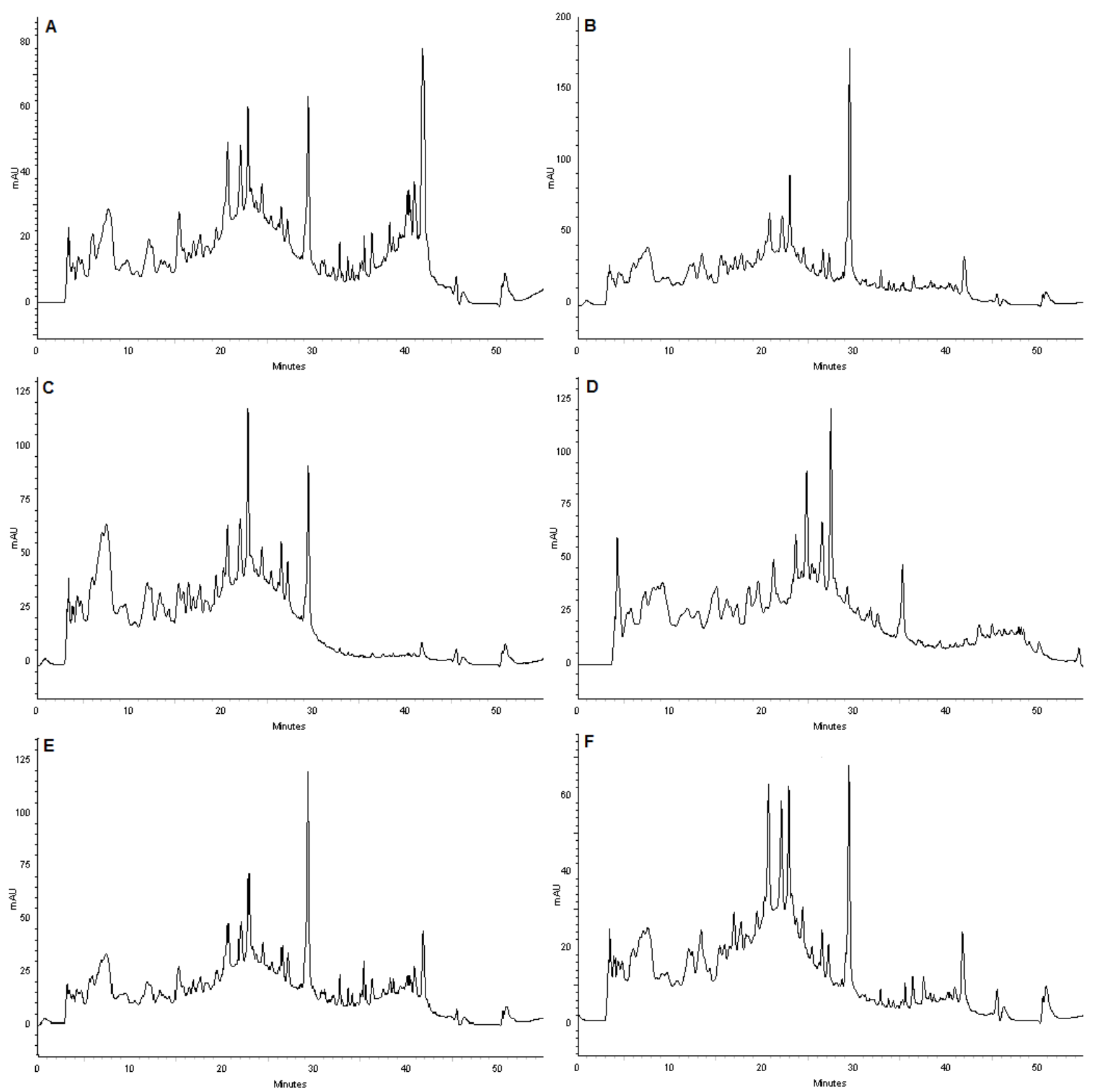

FIGURA 3. Perfil cromatográfico das extrações a quente das frondes de $D$. sellowiana. A) INF-E, B) INF-HÁ, C) SOX-E, D) SOX-HÁ, E) DEC-E, F) DEC-HÁ

pelas polaridades diferentes entre este grupo de substâncias e o solvente extrator.

Resultados semelhantes ao da atividade antioxidante pelo método fosfomolibdênio foram encontrados por Bora et al. (2005) utilizando as frondes de Dicksonia sellowiana extraídas por meio de Soxhlet, apresentando atividade de $32,87 \%$ comparado com o padrão vitamina $\mathrm{C}$, os resultados encontrados nas extrações padronizadas pelo diversos métodos demonstra que a variação do solvente e do método extrativo utilizado é possível conseguir extratos com menor ou maior poder redutor.
A variação dos resultados obtidos nas técnicas de conteúdos totais e nas atividades antioxidantes foi aplicado em um gráfico de box plot para estudo destas variações (figura 4). Esta metodologia permite uma visualização da variação dos resultados obtidos, o intervalo de variação dos dados, os valores médios, assim como as comparações entre a concentração dos diferentes conteúdos e dos resultados antioxidantes. O eixo horizontal corresponde ao fator de interesse e o eixo vertical a variável a ser analisada, e tanto a altura da caixa como o tamanho fornecem informações sobre a dispersão dos dados. Observa-se que a maior 
TABELA 1. Teor de fenóis totais, flavonoides totais, proantocianidinas totais, esteroides totais e atividade antioxidante frente ao radical DPPH e complexo fosfomolibdênio dos extratos brutos das frondes de Dicksonia sellowiana obtidos por diversos métodos extrativos. Resultados expressos em termos de média \pm desvio padrão.

\begin{tabular}{|c|c|c|c|c|c|c|}
\hline & FenT & FlavT & ProT & EstT & DPPH & Fosfo \\
\hline & $\left(m E q G . g^{-1}\right) \pm D P$ & $\left(m E q Q . g^{-1}\right) \pm D P$ & $\left(m E q C . g^{-1}\right) \pm D P$ & $\left(m E q E . g^{-1}\right) \pm D P$ & $\left(\mathrm{IC} 50\right.$ ug. $\left.\mathrm{ml}^{-1}\right) \pm \mathrm{DP}$ & $(\%$ Vit C $) \pm D P$ \\
\hline US-E & $159,9^{a} \pm 0,03$ & $21,1^{\mathrm{b}} \pm 0,24$ & $78,1^{\mathrm{d}} \pm 0,05$ & $29,4^{\mathrm{b}} \pm 0,19$ & $36,5^{\mathrm{e}} \pm 0,04$ & $17,6^{a} \pm 0,20$ \\
\hline US-HA & $181,1 \pm 0,06$ & $22,7 \pm \pm 0,09$ & $85,6 \pm 0,16$ & $26,5^{\mathrm{a}} \pm 0,17$ & $35,2 \pm 0,65$ & $28,8 \pm 0,43$ \\
\hline TUR-E & $174,5^{c} \pm 0,02$ & $29,2^{\mathrm{e}} \pm 0,17$ & $89,2^{q} \pm 0,15$ & $65,8 \pm 0,27$ & $33,8 \pm 1,17$ & $24,2^{\mathrm{c} d} \pm 0,27$ \\
\hline TUR-HA & $213,1 \pm 0,165$ & $38,6 \pm 0,18$ & $109,6 \pm 0,23$ & $37,9 \pm 0,55$ & $27,5^{\mathrm{b}} \pm 0,13$ & $39,7 \pm 0,96$ \\
\hline MAC-E & $192,7 \mathrm{~g} \pm 0,12$ & $34,3 \pm 0,04$ & $91,1^{\mathrm{n}} \pm 0,09$ & $52,8 \pm 0,06$ & $35,5^{\mathrm{de}} \pm 0,21$ & $25,9^{\mathrm{de}} \pm 0,53$ \\
\hline MAC-HA & $180,7 \mathrm{e} \pm 0,45$ & $33,5 ₫ \pm 0,81$ & $80,0 \pm \pm 0,90$ & $48,1 \pm 0,14$ & $36,5^{\mathrm{e}} \pm 0,46$ & $23,0 \mathrm{bc} \pm 1,10$ \\
\hline INF-E & $178,2^{\mathrm{d}} \pm 0,01$ & $31,5^{\ddagger} \pm 0,05$ & $76,3^{\mathrm{c}} \pm 0,12$ & $67,7^{k} \pm 0,75$ & $37,3^{ \pm} \pm 0,10$ & $22,5^{\mathrm{b}} \pm 0,61$ \\
\hline INF-HA & $215,8 \pm 0,04$ & $39,1 \pm 0,62$ & $113,1 \times \pm 0,69$ & $58,3^{n} \pm 0,03$ & $37,0 \pm 0,02$ & $22,9 \mathrm{bc} \pm 0,23$ \\
\hline DEC-E & $193,2^{n} \pm 0,05$ & $35,7^{n} \pm 0,40$ & $100,5 \pm 0,11$ & $73,2 \pm 0,05$ & $34,4^{\mathrm{cd}} \pm 0,13$ & $27,1^{\mathrm{e}} \pm 0,46$ \\
\hline DEC-HA & $256,5^{\ltimes} \pm 0,10$ & $44,7 \pm 0,06$ & $140,4 \pm 0,12$ & $59,3 \pm 0,07$ & $25,2^{a} \pm 0,20$ & $58,4^{n} \pm 0,36$ \\
\hline SOX-E & $180,4 \pm 0,07$ & $24,1 \pm 00,26$ & $54,7 a \pm 0,23$ & $39,4 \pm \pm 0,09$ & $41,5 ₫ 0,07$ & $22,7 \mathrm{bc} \pm 0,41$ \\
\hline SOX-HÁ & $163,9 \bullet \pm 0,12$ & $18,7 \mathrm{a} \pm 0,16$ & $67,0 \triangleright \pm 0,06$ & $34,4 \div \pm 0,16$ & $42,6 ₫ \pm 0,17$ & $22,2^{\circ} \pm 0,23$ \\
\hline
\end{tabular}

FenT: Fenólicos totais, FlavT: Flavonoides totais, ProT: Proantocianidinas totais, EstT: Esteroides totais, Fosfo: Fosfomolibdênio, IC50: concentração inibitória de $50 \%$. $\pm \mathrm{DP}= \pm$ desvio padrão. ${ }^{*}$ Resultados seguidos pela(s) mesma (s) letra (s) não difere estatisticamente $(p<0,05)$ entre si, pelo teste de Tukey.

diferença entre os dados obtidos nas extrações com ambos os solventes esta na quantidade de polifenóis, proantocianidinas e esteroides, este fator justifica-se pela escolha do solvente extrator onde a presença da água confere uma polaridade mais alta que no etanol.

A análise dos principais componentes (PCA) é uma análise multivariada que vem sendo muito utilizada em diversos estudos, mostrando a semelhança entre as amostras testadas através de uma matriz (Hossain et al., 2011; Patras et al., 2011; Campos et al., 2014). Para esta análise utilizou-se todos os dados obtidos nos doseamentos totais e as atividades antioxidantes em triplicata. $O$ fator 1 que explica $75,90 \%$ da análise refere-se aos doseamentos totais e o fator 2 que explica 19,47\%

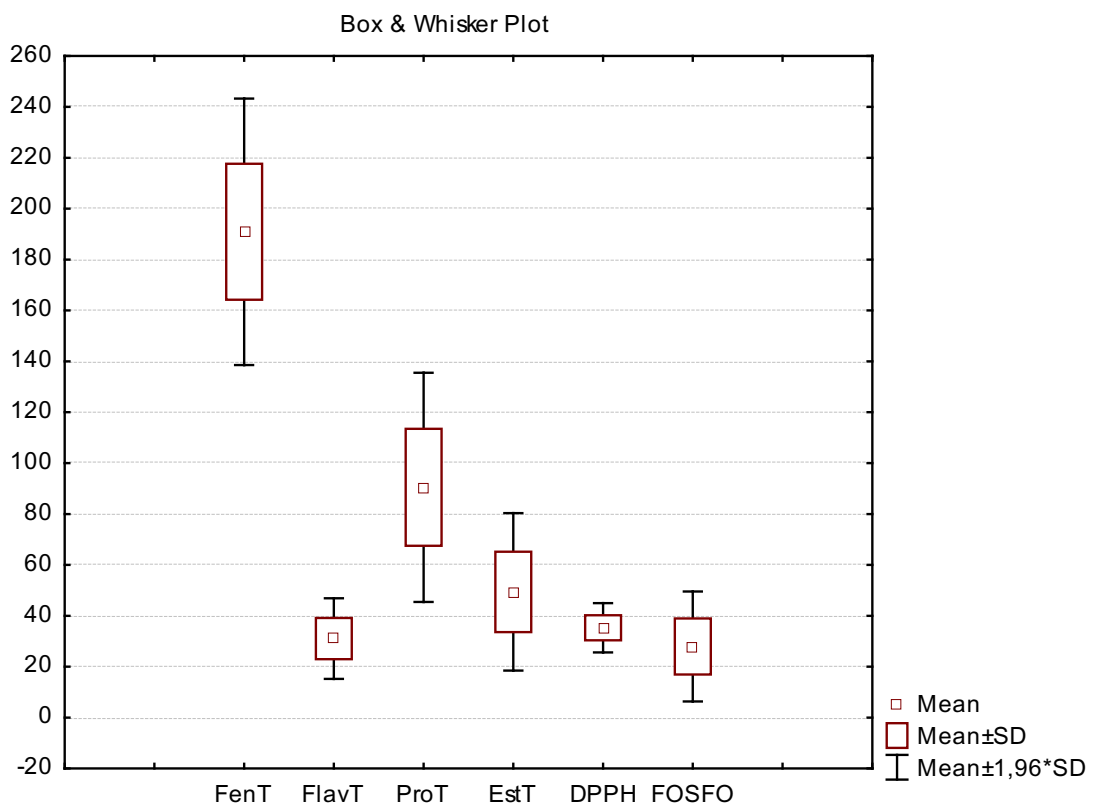

FIGURA 4. Box-plot de média e variação dos fatores utilizados. FenT - Fenólicos totais. FlavT - Flavonoides totais. ProT - Proantocianidinas totais. EstT - Esteroides totais

Rev. Bras. PI. Med., Campinas, v.18, n.1, supl. I, p.230-239, 2016. 


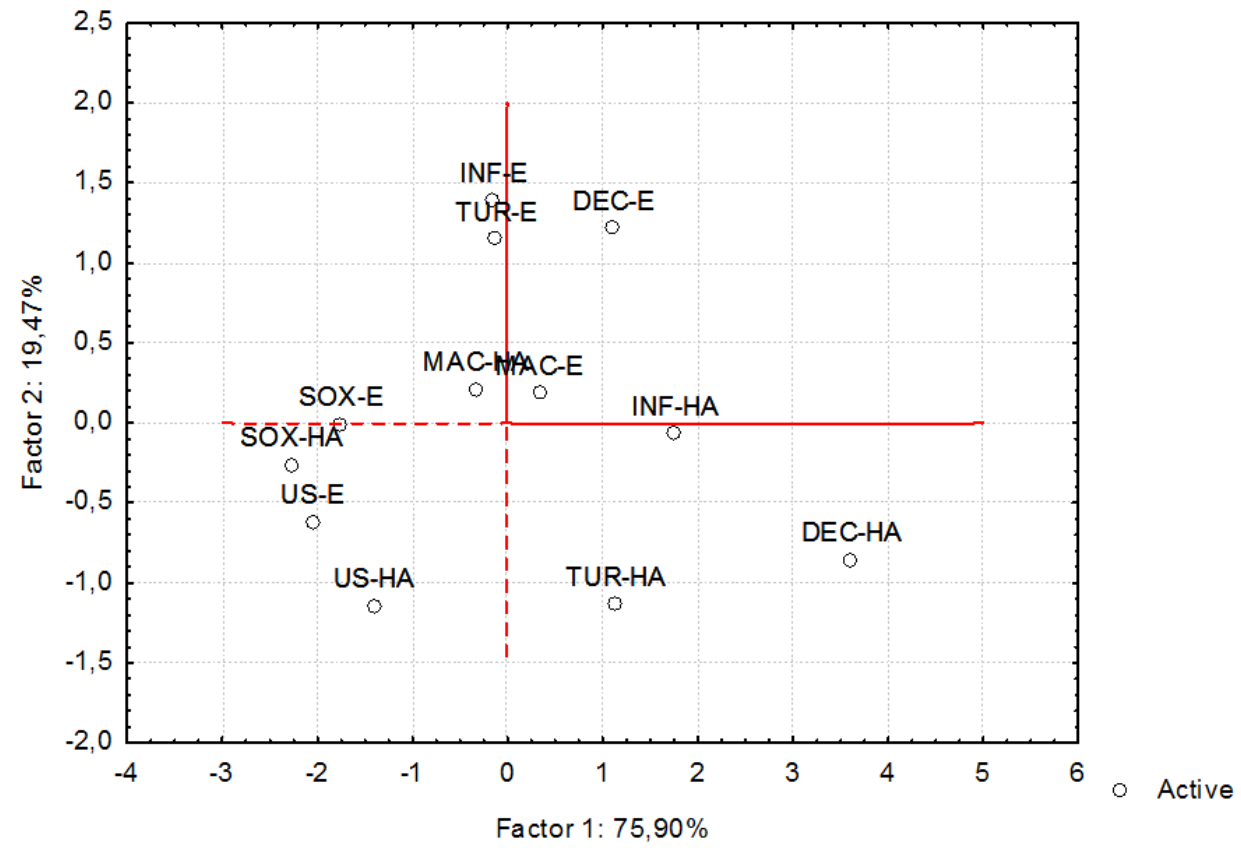

FIGURA 5. Análise dos principais componentes (PCA) pela similaridade entre as características químicas e as propriedades antioxidantes dos extratos obtidos por diversas técnicas com dois solventes extrativos

refere-se às atividades antioxidantes e as amostras são consideradas semelhantes se estiverem no mesmo quadrante cartesiano ou à uma distância máxima de um quadrado, em todos os lados.

Analisando a figura 5 nota-se a diferença entre os diversos tipos de extratos, mostrando a semelhança entre alguns extratos como SOX-E, SOX-HA e US-E, mas também mostrando que os extratos TUR-HA e DEC-HA são os extratos que se diferenciam dos demais, por apresentarem maios teores de polifenóis e melhores atividades antioxidantes em ambos os métodos..

\section{CONCLUSÃO}

Os resultados mostraram que as técnicas de extração e a natureza do solvente extrator afetam diretamente nos rendimentos extrativos e no teor de metabólitos presentes, podendo interferir em atividades biológicas e farmacológicas, porém, é necessário conhecer a natureza do material a ser estudado. Através do perfil cromatográfico foi possível avaliar que existe diferença entre os métodos extrativos, principalmente nos extratos etanólicos a frio e quente. A extração por Soxhlet, obtendo os menores resultados nos teores de metabólitos, foi a extração que apresentou maior rendimento, sendo considerado o extrato total. Com o auxílio de PCA é possível diferenciar amostras com diversas variáveis mostrando os resultados de maneira estatística. As extrações por DEC-HA e TUR-HA foram as que obtiveram os melhores resultados no conteúdo de fenólicos e atividades biológicas demonstrando que o solvente e os métodos extratores são mais seletivos para extração destes metabólitos para as frondes da espécie vegetal Dicksonia sellowiana.

\section{AGRADECIMENTOS}

Os autores agradecem ao Programa de Pós-graduação em Ciências Farmacêuticas da Universidade Federal do Paraná, a CAPES e ao CNPq pelo apoio de bolsas de estudo.

\section{REFERÊNCIAS}

BAMPOULI, A. et al. Comparison of different extraction methods of Pistacia lentiscus var. chia leaves: Yield, antioxidant activity and essential oil chemical composition. Journal of Applied Research on Medicinal and Aromatic Plants, v.1, n.3, p.81-91, 2014.

BORA, K. et al. Determinação da concentração de polifenóis e do potencial antioxidante das diferentes frações do extrato de folhas de Dicksonia sellowiana, (Presl.) Hook, DICKSONIACEAE. Visão Acadêmica, v.6, n.2, p.6-15, 2005.

BURNS, R.E. Method for estimation of tannin in grain sorghum. Agronomy Journal, v.63, n.3, p.511-512, 1971.

BRASIL. Instrução normativa MMA $n^{\circ} 6$, de 23 de setembro de 2008. Disponível em: http://www.mma.gov. br/estruturas/179/_arquivos/179_05122008033615.pdf Acesso em 31 de março de $201 \overline{6}$. 
BRASIL. Ministério do meio ambiente MMA. - Resolução $n^{\circ} 35$, de 27 de abril de 2011. Disponível em: http://www. mma.gov.br/estruturas/222/_arquivos/res35_222.pdf Acesso em 31 de março 2016.

CAMPOS, R. et al. Multivariate analysis between the phytochemical features and antioxidant properties of the stems of Bauhinia glabra jacq. (FABACEAE). International Journal of Pharmacy and Pharmaceutical Sciences, v.6, n.8, p.151-155, 2014.

CHANG, C.C. et al., Estimation of total flavonoid content in propolis by two complementary colorimetric methods. Journal of Food and Drug Analysis, v.10, n.3, p.178182, 2002.

CITES (Convention on International Trade in Endangered Species of Wild Fauna and Flora). Apêndice 3. 2015 Disponível em http://www.cites.org/ eng/app/appendices.php., Acessado em 23 de maio de 2015.

CORRÊA, M.P. Dicionário de plantas úteis do Brasil e das exóticas cultivadas. 1.ed. Brasília: Ministério da Agricultura, Instituto Brasileiro de Desenvolvimento Florestal, 646p. 1984c.

FERNANDES, I. Taxonomia e fitogeografia de Cyatheaceas e Dicksoniaceae nas regiões Sul e Sudeste do Brasil. 1997. 450p. Tese (Doutorado Ciências Biológicas) - Departamento de Botânica, Universidade de São Paulo, São Paulo.

GIL-CHÁVEZ, G.J. et al. Technologies for extraction and production of bioactive compounds to be used as nutraceuticals and food ingredients: an overview. Reviews In Food Science And Food Safety, v.12, n.1, p.5-23, 2013.

GNOATTO, S.C.B. et al. Influência do método de extração nos teores de metilxantinas em erva-mate (I/ex paraguariensis A. ST.- Hil., Aquifoliaceae). Quimica Nova, v.30, n.2, p.304-307, 2007.

HERZI, N. et al. Comparison of different methods for extraction from Tetraclinis articulata: yield, chemical composition and antioxidant activity. Food Chemistry, v.141, n.4, p.3537-3545, 2013.

HOSSAIN, M.B. et al. Application of principal component and hierarchical cluster analysis to classify different spices based on in vitro antioxidant activity and individual polyphenolic antioxidant compounds. Journal of Functional Foods, v.3, n.3, p.179-189, 2011.

KARABEGOVIĆ, I.T. et al. The effect of different extraction techniques on the composition and antioxidant activity of cherry laurel (Prunus laurocerasus) leaf and fruit extracts. Industrial Crops and Products, v.54, p.142148, 2014.

KIM, E.; GOLDBERG, M. Serum Cholesterol Assay Using a Stable Liebermann-Burchard Reagent. Clinical Chemistry, v.15, n.12, p.1171-1179, 1969.

JOLY, A.B. Botânica: Introdução à taxonomia vegetal. 7.ed. São Paulo: Ed. Nacional, 1985. 777p.

MARQUESINI, N.R. Plantas usadas como medicinais pelos índios do Paraná e Santa Catarina, Sul do Brasil: Guarani, Kaingãng, Xokleng, Ava-Guarani, Kraô e Cayua. 1995. 290p. Dissertação (Mestrado - Ciências Biológicas) - Departamento de Botânica, Universidade Federal do Paraná, Curitiba.
MENSOR, L.L. et al. Screening of brazilian plant extracts for antioxidant activity by the use of DPPH free radical method. Phytoterapy Research, v.15, n.2, p.127-130, 2001.

MIELKE, E.J.C. Análise da cadeia produtiva e comercialização do xaxim Dicksonia sellowiana, no Estado do Paraná. 2002. 90p. Dissertação (Mestrado em engenharia florestal) Universidade Federal do Paraná.

OLIVEIRA, V.B. Estudo fitoquímico e atividades biológicas da espécie vegetal Dicksonia sellowiana (DICKSONIACEAE). 2012. 126p. Dissertação (Mestrado -Ciências Farmacêuticas) - Departamento de Farmácia, Universidade Federal do Paraná, Curitiba.

OLIVEIRA, V.B. et al . Avaliação do potencial antioxidante frente à oxidação lipídica e da toxicidade preliminar do extrato e frações obtidas das frondes de Dicksonia sellowiana (Presl.) Hook. Revista Brasileira de Plantas Medicinais, v.17, n.4, p.614-621, 2015.

PATRAS, A. et al. Application of principal component and hierarchical cluster analysis to classify fruits and vegetables commonly consumed in Ireland based on in vitro antioxidant activity. Journal of Food Composition and Analysis, v.24, p.250-256, 2011.

PRIETO, P. et al. Spectrophotometric quantitation of antioxidant capacity through the formation of a Phosphomolybdenum Complex: specific application to the determination of vitamin E. Analytical Biochemistry, v.269, n.2, p.337-341, 1999.

RATTMANN, Y.D. et al. Standardized extract of Dicksonia sellowiana Presl. Hook (Dicksoniaceae) decreases oxidative damage in cultured endothelial cells and in rats. Journal of Ethnopharmacology, v.133, p.9991007, 2011.

ROCKENBACH, I.I. et al. Influência do solvente no conteúdo total de polifenóis, antocianinas e atividade antioxidante de extratos de bagaço de uva (Vitis vinifera) variedades Tannat e Ancelota. Ciência e Tecnologia de Alimentos., v.28, supl. p. 238-244, 2008

SLINKARD, K.; SINGLETON, V.L. Total Phenol Analysis: Automation and Comparison with Manual Methods. American Journal of Enology and Viticulture, v.28, n.1, p.49-55, 1977.

TIWARI, P. et al. Phytochemical screening and Extraction: A Review. Internationale Pharmaceutica Sciencia, v.1, n.1, p.98-106, 2011.

TRYON, R.M.; TRYON, A F. Ferns and allied plants with special reference to Tropical America. 1.ed. New York: Spring - Verlag., 1982. p. $144-149$.

VEBER, J. et al. Determinação dos compostos fenólicos e da capacidade antioxidante de extratos aquosos e etanólicos de Jambolão (Syzygium cumini L.). Revista brasileira plantas medicinais, v.17, n.2, p.267-273, 2015.

VONGSAK, B. et al. Maximizing total phenolics, total flavonoids contents and antioxidant activity of Moringa oleifera leaf extract by the appropriate extraction method. Industrial Crops and Products, v.44, p.566-571, 2013. YAMINI, Y. et al. Comparison of essential oil compositions of Salvia mirzayanii obtained by supercritical carbon dioxide extraction and hydrodistillation methods. Food Chemistry, v.108, n.1, p.341-346, 2008.

Rev. Bras. PI. Med., Campinas, v.18, n.1, supl. I, p.230-239, 2016. 